\title{
Effect of Chitosan-Based Coatings on the Shelf Life of Salmon (Salmo salar)
}

\author{
Bartolomeu W. S. Souza, ${ }^{\dagger}$ Miguel A. Cerqueira, ${ }^{\dagger}$ Héctor A. Ruiz, ${ }^{\dagger}$ \\ Joana T. Martins, ${ }^{\dagger}$ Alicia Casariego, ${ }^{\S}$ José A. Teixeira, $^{\dagger}$ And \\ ANTÓNIO A. VICENTE* ${ }^{*}$ \\ ${ }^{\dagger}$ IBB - Institute for Biotechnology and Bioengineering, Centre of Biological Engineering, \\ Universidade do Minho, Campus de Gualtar, 4710-057 Braga, Portugal, and ${ }^{\S}$ Instituto de Farmacia y \\ Alimentos, Universidad de la Habana, Ave. 23, No. 21425, entre 214 y 222, La Lisa CP 13600 , \\ Ciudad de La Habana, Cuba
}

\begin{abstract}
This study aimed at determining the effect of chitosan coating on shelf life extension of salmon (Salmo salar) fillets. The success of edible coatings depends highly on their effective wetting capacity of the surfaces on which they are applied. In this context in a first stage the surface properties of salmon fillets and the wetting capacity of the coatings on fish were evaluated. In terms of wettability there were no significant differences $(p>0.05)$ between the solutions presenting higher values (solutions $1-4$ ); therefore, solution 1 with a spreading coefficient $\left(W_{\mathrm{s}}\right)$ of $-4.73 \mathrm{mN} \mathrm{m}^{-1}$, was chosen to be subsequently analyzed and applied on fish fillets. For shelf life analyses the fillets were coated and stored at $0{ }^{\circ} \mathrm{C}$ for 18 days. The control and coated fish samples were analyzed periodically for total aerobic plate count (TPC), $\mathrm{pH}$, total volatile base nitrogen (TVB-N), trimethylamine (TMA), thiobarbituric acid (TBA), and ATP breakdown products ( $K$ value). The results showed that fish samples coated with chitosan presented a significant reduction $(p<0.05)$ for $\mathrm{pH}$ and $K$ value after 6 days and for TVB, TMA, and TBA values after 9 days of storage, when compared to control samples. In terms of microbial growth, a slower increase in TPC was observed for the coated fish, indicating that chitosan-based coatings were effective in extending for an additional 3 days the shelf life of the salmon. These results demonstrate that chitosan-based coatings may be an alternative for extending the shelf life of salmon fillets during storage at $0{ }^{\circ} \mathrm{C}$.
\end{abstract}

KEYWORDS: Edible coatings; shelf life; chitosan; Salmo salar

\section{INTRODUCTION}

Fresh fish is among the most perishable food products, and the monitoring and control of fish quality are the main goals in the fish industry. Postharvest biochemical and microbial changes in fish tissue depend very significantly upon the factors that control the concentration of substrates and metabolites associated with microbial contamination and the conditions after catching (1). Inadequate postcapture handling induces both microbial and endogenous enzyme activities and muscle autolysis, leading to protein degradation and loss of functionality. In particular, seafood products contain high levels of polyunsaturated fatty acids that are easily attacked by oxygen-derived free radicals, resulting in lipid peroxidation and meat rancidity (2). Furthermore, lipid oxidation causes fish rancidity, rendering the product unacceptable for human consumption.

Many indices have been used for the measurement of fish quality during storage. Spectrophotometric detection of the malonaldehyde-thiobarbutiric acid (TBA) complex has been widely used for measuring lipid oxidation in food and biological

*Corresponding author (phone +351.253 .604419 ; fax +351.253 .678 .986 ; e-mail avicente@deb.uminho.pt). tissues $(3,4)$. Changes in the microbial population and chemical changes, including trimethylamine (TMA) content and total volatile base nitrogen (TVB-N), have been proposed as indices of deterioration of fish quality $(5,6)$. Once endogenous enzymes in fish degrade adenine nucleotides during the early stages of the storage period (7), the determination of adenine nucleotides and their degradation products has also been used as a chemical index of fish freshness. In post-mortem fish muscle, degradation of adenosine triphosphate (ATP) takes place according to the following sequence: ATP $\rightarrow$ ADP $\rightarrow$ AMP inosine monophosphate $(\mathrm{IMP}) \rightarrow$ inosine $(\mathrm{HxR}) \rightarrow$ hypoxanthine $(\mathrm{Hx})(8)$. The $K$ value, defined as the ratio of the sum of inosine and hypoxanthine to the sum of ATP and related catabolite compounds, expressed as a percentage, is used extensively as a commercial index for the estimation of fish freshness (9).

The increasing demand for fresh refrigerated seafood with an extended shelf life has intensified the search for technologies that support fresh fish utilization, numerous studies being currently focused on using natural ingredients to enhance fish quality and shelf life (10). One of the main developments is the utilization of edible coatings for food packaging, designed to replace, at least partially, the use of chemical preservatives. 
Chitosan is a nontoxic, biodegradable, and biocompatible natural polymer. Several authors have reported the use of chitosan as an antimicrobial and antioxidant agent in muscle foods $(11-13)$. Moreover, chitosan also has the potential of being applied for food packaging, especially in edible films and coatings (14-16). The polycationic properties of chitosan provide this polymer with the possibility of forming films by the breakage of polymer segments and subsequent re-forming of the polymer chain into a film matrix or gel; this can be achieved by evaporating a solvent, thus creating hydrophilic and hydrogen bonding and/or electrolytic and ionic cross-linking (17). These films are excellent oxygen barriers, and their mechanical properties are comparable to those of many medium-strength commercial polymer films $(17-20)$.

The coating process involves wetting of the food product by the coating solution, where a penetration of the solution (40), followed by adhesion between these two commodities, may occur. The wetting stage (spreadability) is very important, because if the suitability of the coating for the object to be coated is ideal, the time interval necessary for such an operation is minimal, or, in other words, spreadability is virtually spontaneous (14).

The objectives of this study are to characterize the surface properties of the food to be coated and the wetting properties of the chitosan coatings and to determine the effects of surfactant concentration and polymer concentration on the wettability of chitosan coatings. This characterization is made to evaluate the effect of the application of chitosan-based coatings in the shelf life extension of sliced salmon fillets stored at $0{ }^{\circ} \mathrm{C}$. This evaluation was performed through the measurement of microbiological and physicochemical properties of the salmon throughout storage.

\section{MATERIALS AND METHODS}

Coating Materials. The materials used to prepare the edible coating solutions were chitosan (from lobster of the Cuban coasts) obtained in the Pharmaceutical Laboratories Mario Muñoz, Cuba, with a molar mass of $309 \mathrm{~g} / \mathrm{mol}$ and degree of deacetylation of $90 \%$, Tween 80 (Acros Organics, Geel, Belgium) as surfactant, lactic acid 90\% (Merck, Darmstadt, Germany), and distilled water.

Preparation of Samples for Contact Angle Measurements and Shelf Life Determinations. Atlantic salmon (Salmo salar) was obtained from a local market in Braga, Portugal. The salmon samples were headed, gutted, filleted, and cut into slices (200 g average weight slices). Salmon slices were then transported to the laboratory in polystyrene boxes with an appropriate quantity of flaked ice.

Coating Solutions. The coating solutions were prepared by dissolving the chitosan $(1.0,1.5$, or $2.0 \% \mathrm{w} / \mathrm{v})$ in a $1 \%(\mathrm{v} / \mathrm{v})$ lactic acid solution with agitation using a magnetic stirrer during $2 \mathrm{~h}$ at room temperature $\left(20^{\circ} \mathrm{C}\right)$. Tween 80 was added as a surfactant at concentrations between 0.1 and $0.2 \%(\mathrm{w} / \mathrm{v})(14)$.

Critical Surface Tension. According to Zisman (21), in systems having a surface tension lower than $100 \mathrm{mN} \mathrm{m}^{-1}$ (low-energy surfaces), the contact angle formed by a drop of liquid on a solid surface will be a linear function of the surface tension of the liquid, $\gamma_{\mathrm{LV}}$ (where phase $\mathrm{V}$ is air saturated with the vapor of the liquid, L). Zisman's method is applicable only for low-energy surfaces; therefore, it is necessary to determine the surface energy of salmon slices.

For a pure liquid, if polar $\left(\gamma_{\mathrm{L}}^{\mathrm{p}}\right)$ and dispersive $\left(\gamma_{\mathrm{L}}^{\mathrm{d}}\right)$ interactions are known and if $\theta$ is the contact angle between that liquid and a solid, the interaction can be described in terms of the reversible work of adhesion (21), $W_{\mathrm{a}}$, as

$$
W_{\mathrm{a}}=W_{\mathrm{a}}^{\mathrm{d}}+W_{\mathrm{a}}^{\mathrm{p}} \Leftrightarrow W_{\mathrm{a}}=2\left(\sqrt{\gamma_{\mathrm{S}}^{\mathrm{d}} \gamma_{\mathrm{L}}^{\mathrm{d}}}+\sqrt{\gamma_{\mathrm{S}}^{\mathrm{p}} \gamma_{\mathrm{L}}^{\mathrm{p}}}\right)
$$

where $\gamma_{S}^{\mathrm{p}}$ and $\gamma_{\mathrm{S}}^{\mathrm{d}}$ are the polar and dispersive contributions of the surface of the studied solid. Rearranging eq 1 yields

$$
\frac{1+\cos \theta}{2} \times \frac{\gamma_{\mathrm{L}}}{\sqrt{\gamma_{\mathrm{L}}^{\mathrm{d}}}}=\sqrt{\gamma_{\mathrm{S}}^{p}} \times \sqrt{\frac{\gamma_{\mathrm{L}}^{\mathrm{p}}}{\gamma_{\mathrm{L}}^{\mathrm{d}}}}+\sqrt{\gamma_{\mathrm{S}}^{\mathrm{d}}}
$$

The contact angle determinations of at least three pure compounds, bromonaphthalene (Merck), formamide (Merck), and ultrapure water, on the surface of salmon fillets combined with the respective dispersive and polar component values will allow the calculation of both the independent variable

$$
\left(\sqrt{\frac{\gamma_{L}^{\mathrm{p}}}{\gamma_{\mathrm{L}}^{\mathrm{d}}}}\right)
$$

and the dependent variable

$$
\frac{1+\cos \theta}{2} \times \frac{\gamma_{\mathrm{L}}}{\sqrt{\gamma_{\mathrm{L}}^{\mathrm{d}}}}
$$

from eq 2.

The surface tension and the dispersive and polar components were, respectively, $72.10,19.90$, and $52.20 \mathrm{~m} \mathrm{~N} \mathrm{~m}^{-1}$ for water, $44.40,44.40$, and $0.00 \mathrm{~m} \mathrm{~N} \mathrm{~m}^{-1}$ for bromonaphtalene, and $56.90,23.50$, and $33.40 \mathrm{~m} \mathrm{~N} \mathrm{~m}^{-1}$ for formamide (22).

The estimation of the critical surface tension $\left(\gamma_{c}\right)$ was performed by extrapolation from Zisman plots (21), the critical surface tension $\left(\gamma_{c}\right)$ being defined as

$$
\gamma_{\mathrm{c}}=\lim \gamma_{\mathrm{LV}} \quad \text { as } \theta \rightarrow 0
$$

Wettability. Wettability was evaluated by determining the values of the spreading coefficient $\left(W_{\mathrm{s}}\right)$ and the works of adhesion $\left(W_{\mathrm{a}}\right)$ and cohesion $\left(W_{\mathrm{c}}\right)$. The surface tension of the coating solution was measured by the pendant drop method using Laplace-Young's approximation (23). The contact angle $(\theta)$ of a liquid drop on a solid surface is defined by the mechanical equilibrium of the drop under the action of three interfacial tensions: solid-vapor $\left(\gamma_{\mathrm{SV}}\right)$, solid-liquid $\left(\gamma_{\mathrm{SL}}\right)$, and liquid-vapor $\left(\gamma_{\mathrm{LV}}\right)$. The equilibrium spreading coefficient $\left(W_{\mathrm{s}}\right)$ is defined by eq 4 (24) and can only be negative or zero.

$$
W_{\mathrm{s}}=W_{\mathrm{a}}-W_{\mathrm{c}}=\gamma_{\mathrm{SV}}-\gamma_{\mathrm{LV}}-\gamma_{\mathrm{SL}}
$$

$W_{\text {a }}$ and $W_{\mathrm{c}}$ are the works of adhesion and cohesion, defined by eqs 5 and 6 , respectively.

$$
\begin{gathered}
W_{\mathrm{a}}=\gamma_{\mathrm{LV}}+\gamma_{\mathrm{SV}}-\gamma_{\mathrm{SL}} \\
W_{\mathrm{c}}=2 \gamma_{\mathrm{LV}}
\end{gathered}
$$

Contact angle $(\theta)$ and liquid-vapor surface tension $\left(\gamma_{\mathrm{LV}}\right)$ were measured in a face contact angle meter (OCA 20, Dataphysics, Bad Vilbel, Germany). The samples of the coatings were taken with a $500 \mathrm{~mL}$ syringe (Hamilton, Bonaduz, Switzerland), with a needle of $0.75 \mathrm{~mm}$ of diameter. The contact angle at the fillet surface was measured by the sessile drop method (25). Measurements were made in $<30 \mathrm{~s}$. Twenty replicates of contact angle and surface tension measurements were obtained at 21.1 $( \pm 0.4){ }^{\circ} \mathrm{C}$.

Application of Coating and Sample Preparation. On the basis of the wettability test the best chitosan coating forming solution to dip salmon fillets was the one that presented $W_{\mathrm{s}}$ values closer to zero. Coating solutions were previously sterilized under UV light ( $254 \mathrm{~nm})$ during $2 \mathrm{~min}$ prior to being applied to fillet samples. Each sample was dipped into the coating solution for $10 \mathrm{~s}$ and dried for $1 \mathrm{~min}$ on a sterile stainless steel wire mesh screen. The sample control group was given a similar treatment but without coating application. For each treatment, salmon fillets $(n=3)$ were individually packed in plastic bags and stored at $0{ }^{\circ} \mathrm{C}$ for 18 days. Fish samples were taken from each package, and microbiological and physicochemical analyses were performed at regular intervals $(0,3,6,9,12,15$, and 18 days).

Chemical Analyses. $\quad$ pH Measurement. Ten grams of each sample (fish muscle) was blended with $100 \mathrm{~mL}$ of distilled water in a blender for $30 \mathrm{~s}$, and the mixture was filtered through Whatman no. 1 filter paper. The $\mathrm{pH}$ of the filtrate was measured using a digital $\mathrm{pH}$-meter (micro $\mathrm{pH}$, Crison, Barcelona, Spain).

Total Volatile Base Nitrogen (TVB- $N$ ) and Trimethylamine (TMA). Fish extracts for the determination of TVB-N and TMA were prepared by homogenizing $100 \mathrm{~g}$ of fish sample with $200 \mathrm{~mL}$ of $7.5 \%$ (v/v) aqueous 
trichloroacetic acid (TCA) solution in a laboratory homogenizer for $1 \mathrm{~min}$ at high speed. The homogenate was centrifuged at $1000 \mathrm{~g}$ for $5 \mathrm{~min}$, and the supernatant liquid was then filtered through Whatman no. 1 filter paper. TVB-N was measured by steam distillation of the TCA-fish extract, using the modified method of Malle and Tao (26). The same experimental procedure of TVB-N was used for TMA measurement (27). The only difference was the addition of $20 \mathrm{~mL}$ of $35 \%$ (v/v) formaldehyde to the distillation tube to block the primary and secondary amines, leaving only the tertiary amines to react. The amounts of TVB-N and TMA were calculated from the volume of sulfuric acid used for titration, and the results were expressed in milligrams of nitrogen per $100 \mathrm{~g}$ of sample.

Determination of Thiobarbituric Acid (TBA) Value. The TBA value (as malonaldehyde) was determined colorimetrically according to the method of Porkony and Dieffenbacher as described by Kirk and Sawyer (28). A portion $(200 \mathrm{mg})$ of sample was weighed into a $25 \mathrm{~mL}$ volumetric flask. An aliquot $(1 \mathrm{~mL})$ of 1-butanol was added to dissolve the sample. The mixture was made up to volume and mixed. A portion $(5 \mathrm{~mL})$ of the mixture was pipetted into a dry stoppered test tube, and $5 \mathrm{~mL}$ of TBA reagent (prepared by dissolving $200 \mathrm{mg}$ of 2-TBA in $100 \mathrm{~mL}$ of 1-butanol, which was filtered and stored at $4{ }^{\circ} \mathrm{C}$ for not more than 7 days) was added. The test tubes were stoppered, vortexed, and placed in a water bath at $95^{\circ} \mathrm{C}$ for $120 \mathrm{~min}$ and then cooled. Sample absorbance $\left(A_{\mathrm{s}}\right)$ was measured at $530 \mathrm{~nm}$. A solution of pure water $(5 \mathrm{~mL})$ plus TBA reagent $(5 \mathrm{~mL})$ was used as reagent blank $\left(A_{\mathrm{b}}\right)$. TBA value (mg of malonaldehyde $/ \mathrm{kg}$ of tissue) was obtained by

$$
\mathrm{TBA}=\frac{50 \times\left(A_{\mathrm{s}}-A_{\mathrm{b}}\right)}{200}
$$

Determination of $K$ Value. $K$ value was determined according to the method of Ryder (29). Five grams of skinned fillet obtained from the anterior dorsal regions of the fish was used for the analyses. The fish extract was prepared by homogenizing the sample with $25 \mathrm{~mL}$ of chilled $0.6 \mathrm{~mol} / \mathrm{L}$ perchloric acid at $0{ }^{\circ} \mathrm{C}$ for $1 \mathrm{~min}$. The homogenate was centrifuged at $2000 \mathrm{~g}$ for $10 \mathrm{~min}$, and the $\mathrm{pH}$ of the supernatant was adjusted to $\mathrm{pH} 6.5-6.8$ using a $1 \mathrm{~mol} / \mathrm{L}$ aqueous potassium hydroxide solution (Fluka-Chemika). The potassium perchlorate that precipitated after standing at $2{ }^{\circ} \mathrm{C}$ for $30 \mathrm{~min}$ was removed by filtration through Whatman membrane filter no. 1. The filtrate was made up to $20 \mathrm{~mL}$ and passed through $0.20 \mu \mathrm{m}$ Millipore membrane. The samples were stored at $-80^{\circ} \mathrm{C}$ until further use. Twenty microliter aliquots of these sample were analyzed using a HPLC (Jasco, chromatograph 2080-PU intelligent pump (Jasco, Tokyo, Japan)) equipped with a Jasco 2070-UV intelligent UV-vis detector at $254 \mathrm{~nm}$ and a Jasco AS-2057 Plus intelligent auto sampler with a Nucleosil 120-5 C18 (5 $\mu \mathrm{m}$ particle size, Macherey-Nagel, Düren, Germany) column. Separation of the nucleotide products was achieved using a mobile phase of $0.04 \mathrm{~mol} / \mathrm{L}$ potassium dihydrogen orthophosphate and $0.06 \mathrm{~mol} / \mathrm{L}$ dipotassium hydrogen orthophosphate dissolved in 1:1 ratio in Milli-Q purified distilled water, at a flow rate of $0.8 \mathrm{~mL} \mathrm{~min}^{-1}$. The peaks obtained from fish muscle extracts were identified and quantified through standard solution curves. ATP breakdown products comprising ATP, ADP, AMP, IMP, Hx, and Ino were measured, and the $K$ value was calculated using the equation described by Saito et al. (9):

$$
K \%=\frac{(\mathrm{Ino}+\mathrm{Hx})}{(\mathrm{ATP}+\mathrm{ADP}+\mathrm{AMP}+\mathrm{IMP}+\mathrm{Ino}+\mathrm{Hs})}
$$

Microbiological Analysis. A sample of $25 \mathrm{~g}$ was taken aseptically from each fillet and transferred to a stomacher bag, and $225 \mathrm{~mL}$ of sterilized peptone water (Becton, Dickinson and Co., Le Pont de Claix, France) was added. The mixture was homogenized for 2 min with a Stomacher 3500 (Seward Medical, Worthing, U.K). Samples (0.1 mL) of serial dilutions of salmon slice homogenates were spread on the surface of the appropriate dry medium in Petri dishes for determination of the total aerobic plate count (TPC) on plate count agar (Oxoid, CM325) and incubated at $30^{\circ} \mathrm{C}$ for 3 days. Microbiological data were transformed into logarithms of the number of colony-forming units $(\mathrm{CFU} / \mathrm{g})$.

Statistical Analyses. All measurements were carried out in triplicate. Statistical analyses were performed using analysis of variance (ANOVA) and linear regression analysis. The Tukey test $(\alpha=0.05)$ was used to determine any significance of differences between specific means (SigmaStat, trial version, 2003).

\section{RESULTS AND DISCUSSION}

Critical Surface Tension and Surface Tension of Sliced Salmon Fillets. Determination of the surface tension usually involves the measurement of the contact angles that several standard liquids make with that surface. The surface energy of the solid surface is then related to the surface tensions of the liquids and the contact angles. This method involves an estimation of the critical surface tension of the surface of the solids studied, by extrapolation from the Zisman plot (21).

The determination of the surface tension and of the critical surface tension of the salmon allows the characterization of the surface of its fillets.

Surface tension depends on a number of relatively independent forces, such as dispersion, dipolar, induction, hydrogen-bonding, and metallic interactions (21). The surface of the salmon displays values of critical surface and surface tension of $30.13 \pm 0.12$ and $60.64 \pm 0.47 \mathrm{~m} \mathrm{~N} \mathrm{~m}^{-1}$, respectively. The salmon surface is therefore a low-energy surface $\left(<100 \mathrm{mN} \mathrm{m}^{-1}\right)$ presenting a low dispersive component $\left(18.18 \pm 0.41 \mathrm{mN} \mathrm{m}^{-1}\right)$, which supports its lesser ability to participate in nonpolar interactions. Salmon surface showed a higher polar component $\left(42.46 \pm 0.37 \mathrm{mN} \mathrm{m}^{-1}\right)$, which is usually associated with the high water content found in salmon muscle. A surface with these characteristics interacts with liquid primarily by dispersion forces, influencing the effective spreading of the coating on the salmon surface. The compatibility of the polarity (apolar or polar) of the surface and of the coating may play, therefore, an important role in the wettability of the surface. Additionally, Mikalsky et al. (30) showed that, apart from proteins present in meat, other components such as fat carbon hydroxides, play an important role in the adhesion mechanism of meat. The muscle of salmonids is very rich in apolar components (e.g., fat), featuring a significant apolar influence.

Wettability of Chitosan Solution on Salmon Sliced Fillets. The optimization of the coating solutions composition was based on their ability to spread over a surface and can be made considering three parameters: the spreading coefficient and the adhesion and cohesion coefficients $(14,16)$. The control of adhesion and cohesion coefficients is very important because if the former promotes the spreading of the liquid, the latter promotes its contraction (31), and an adequate equilibrium between these two forces is necessary. The wettability was evaluated by determining the values of the spreading coefficient $\left(W_{\mathrm{s}}\right)$. Wettability is one of the most important properties when the capacity of a solution to coat a designated surface is evaluated. The values of $W_{\mathrm{s}}$ (the best values being those closer to zero) on the salmon surface were determined for coating solutions with different concentrations of chitosan and Tween 80 .

The results in Table 1 show that the spreading coefficient $\left(W_{\mathrm{s}}\right)$ decreased as chitosan and Tween 80 concentrations increased for the surface studied. The addition of a surfactant to the coating solution reduces the interfacial tension and improves the adhesion on the surface to be covered $(16,32)$. Choi et al. (33) reported that the addition of $1 \%$ of Tween 80 to a solution of $1.5 \%$ chitosan improved the compatibility of the chitosan coating solution and apple skin. The improvement of $W_{\mathrm{s}}$ with the addition of Tween 80 was also shown by Ribeiro et al. (31), Casariego et al. (14), and Cerqueira et al. (16). Tween 80 acts by reducing the superficial tension of the liquid and by increasing the value of $W_{\mathrm{s}}$. However, in this case, Tween 80 did not influence $W_{\text {s }}$ values due to the fact that the surface of salmon fillets is very rich in water and has therefore more affinity for polar components. There were no significant differences $(p>0.05)$ between the solutions presenting higher values (solutions 1-4); therefore, solution 1 with a spreading coefficient $\left(W_{\mathrm{s}}\right)$ of $-4.73 \mathrm{mN} \mathrm{m}^{-1}$ was chosen to be subsequently analyzed and applied on fish fillets. 
Table 1. Spreading Coefficient $\left(W_{\mathrm{s}}\right)$ Obtained for the Tested Chitosan Solutions on Salmon Fillets

\begin{tabular}{cccc}
\hline solution & chitosan $(\mathrm{w} / \mathrm{v})$ & Tween $(\mathrm{w} / \mathrm{v})$ & $W_{\mathrm{s}}{ }^{\mathrm{a}}$ \\
\hline 1 & 1.0 & 0.0 & $-4.73 \pm 0.87 \mathrm{a}$ \\
2 & 1.0 & 0.1 & $-4.86 \pm 0.45 \mathrm{a}$ \\
3 & 1.0 & 0.2 & $-6.21 \pm 0.39 \mathrm{abc}$ \\
4 & 1.5 & 0.0 & $-5.47 \pm 0.45 \mathrm{a}$ \\
5 & 1.5 & 0.1 & $-8.52 \pm 0.58 \mathrm{be}$ \\
6 & 1.5 & 0.2 & $-9.13 \pm 0.52 \mathrm{ce}$ \\
7 & 2.0 & 0.0 & $-13.17 \pm 0.98 \mathrm{df}$ \\
8 & 2.0 & 0.1 & $-9.75 \pm 0.52 \mathrm{eg}$ \\
9 & 2.0 & 0.2 & $-12.43 \pm 0.87 \mathrm{fg}$ \\
\hline
\end{tabular}

${ }^{a}$ Values reported are the mean \pm standard deviations $(n=30,95 \%$ confidence interval, at $20.0 \pm 1{ }^{\circ} \mathrm{C}$ ). Different letters indicate a statistically significant difference (Tukey test, $p<0.05$ ).

Chemical Analyses. $p H$ Measurement. The effect of chitosan coating and storage time on the $\mathrm{pH}$ of salmon slices during storage at $0{ }^{\circ} \mathrm{C}$ is shown in Figure 1. The initial $\mathrm{pH}$ of the fish sample was found to be 6.30. The application of the selected chitosan coating indicated no statistically significant effect $(p>$ 0.05 ) on initial $\mathrm{pH}$ values when compared with control salmon sample. After 6 days of storage at $0^{\circ} \mathrm{C}$, the $\mathrm{pH}$ value of the control slices (6.58) was significantly $(p<0.05)$ higher than that of samples treated with chitosan coating (6.47). This $\mathrm{pH}$ increase has a pronounced effect on the quality of the product during storage, especially in terms of sensorial characteristics such as odor, color, and texture, which are negatively affected (34). In general, the increase of $\mathrm{pH}$ values may be related to the fast spoilage of the product, with formation of alkaline autolysis compounds (nitrogenous compounds) and production of bacterial metabolites in the muscle during the post-mortem period. Fan et al. (35) studied the effect of chitosan coatings on the quality and shelf life of silver carp during frozen storage and concluded that the lower $\mathrm{pH}$ of the coated sample can enhance microbial inhibition and contribute to extend the preservation of fish samples by inhibiting the activity of the endogenous proteases.

$T V B-N$ and TMA. TVB-N, a parameter that quantifies the compounds composed of ammonia and primary, secondary, and tertiary amines, is widely used as an indicator of deterioration of muscle tissues (35). The quality and storage life of fish may decrease if they have not been gutted. Fish contain many bacteria in the digestive system, and strong digestive enzymes are produced during the feeding periods, which may cause rapid post-mortem autolysis during the later stage of storage. This may give rise to a strong off-flavor, which is often related to the breakdown of protein and the production of nitrogenous volatile materials (36).

Initial TVB-N values ( 8.05 and $8.06 \mathrm{mg}$ of TVB-N/100g for control and coated samples, respectively) indicate that the fresh salmon was of good quality, in agreement with the relatively low initial TPC count (3.02 $\log _{10}$ CFU/g). Similar TVB-N values have been found for sliced salmon (37). TVB-N contents increased gradually, attaining final values of 32.70 and $28.09 \mathrm{mg} / 100 \mathrm{~g}$ for control and coated samples, respectively, at the end of storage period (Figure 2). These results may be attributed to the faster reduction of bacterial population or to the decrease of the capacity of bacteria for oxidative deamination (35). Moreover, the differences between control and coated samples can be attributed to the antimicrobial activity of chitosan (38).

TMA and nitrogen of trimethylamine (TMA-N) are the most used volatile amines in the fish industry for evaluating freshness and spoilage in marine fish, because they are produced during chilled storage of fish as a result of the bacterial utilization of trimethylamine oxide (TMAO), a naturally occurring osmoregulatory substance found in most marine fish species (39). Although

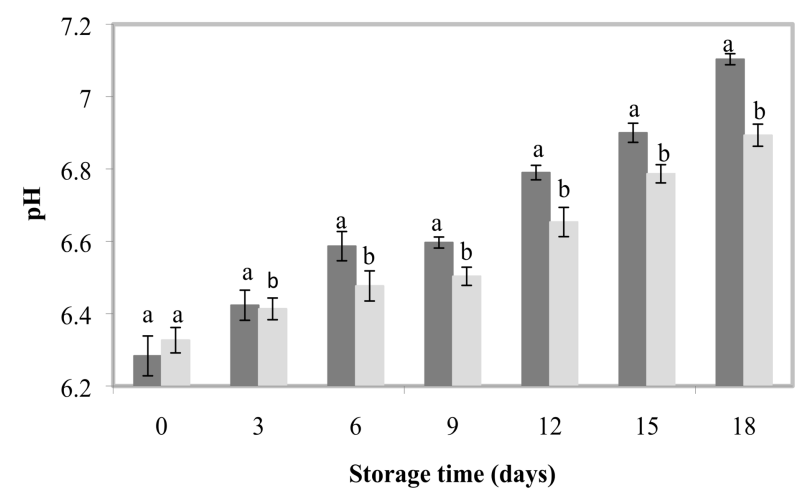

Figure 1. pH values for control (dark gray bars) and coated (light gray bars) samples of salmon fillet during storage at $0{ }^{\circ} \mathrm{C}$. Different letters in the same day indicate a statistically significant difference (Tukey test, $p<0.05$ ).

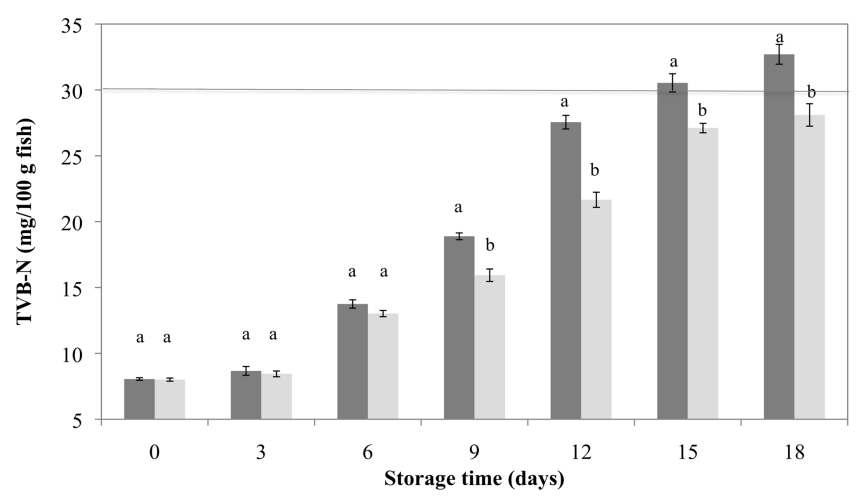

Figure 2. Total volatile base nitrogen (TVB-N) content for control (dark gray bars) and coated (light gray bars) samples of salmon fillet during storage at $0^{\circ} \mathrm{C}$. The horizontal line represents the rejection limit in fish flesh, which is $30 \mathrm{mg}$ of TVB-N/100 $\mathrm{g}$. Different letters in the same day indicate a statistically significant difference (Tukey test, $p<0.05$ ).

TMA-N content in muscle is due to bacterial action, its correlation with bacterial growth is not always obtained (39). The concentration of TMA-N in numerous fatty fishes never reaches $5 \mathrm{mg}$ of TMA-N/100 g, a lower value than the rejection limit in fish flesh, which is usually between 5 and $10 \mathrm{mg}$ of TMA-N/100 g. The concentrations of TMA-N present in the muscle tissue of salmon stored at $0{ }^{\circ} \mathrm{C}$ are shown in Figure 3. The initial TMA values are $0.87 \mathrm{mg}$ of TMA-N/100 $\mathrm{g}$ of muscle for control sample and $0.91 \mathrm{mg}$ of TMA-N/100 g of muscle for coated sample. A slow increase occurs during the first 3 days of storage, with values of 1.39 and $1.33 \mathrm{mg}$ of TMA-N/100 $\mathrm{g}$ being reached.

After 9 days of storage, control samples (without coating) registered higher concentrations of TMA $(2.03 \mathrm{mg}$ of TMA-N/ $100 \mathrm{~g})$ than coated samples $(1.80 \mathrm{mg}$ of TMA-N/100 g). TMA values of both control and treated samples increased gradually, with values of $6.37 \pm 0.14$ and $5.33 \pm 0.29 \mathrm{mg}$ of TMA-N/100 g of flesh being obtained for the control and treated samples, respectively, by the end of the storage period (day 18).

TMA accumulation is a result of bacterial breakdown of TMAO, and this occurs to a significant level only during the exponential phase of microbial growth (39). In this study, the rate of TMA accumulation was slower for the chitosan-coated sample, which showed in 15 days a TMA content of $4.52 \mathrm{mg}$ of TMA-N/100 g, which is lower than the minimum level associated with offensive odor. The TMA concentration observed for these chitosan-coated samples was a clear indication that the fish was still fresh, even after 15 days of storage on ice. The observation of 


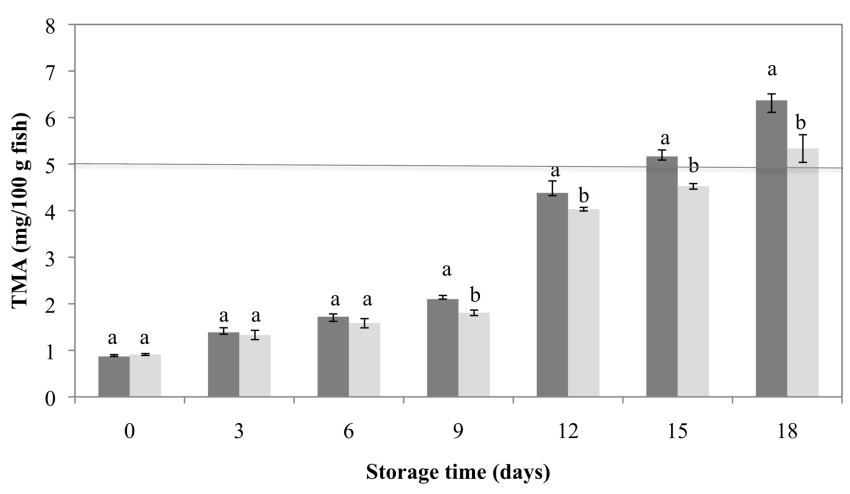

Figure 3. Trimethylamine (TMA) content for control (dark gray bars) and coated (light gray bars) samples of salmon fillet during storage at $0{ }^{\circ} \mathrm{C}$. The horizontal line represents the lower rejection limit in fish flesh, which is usually between 5 and $10 \mathrm{mg}$ of TMA-N/100 g. Different letters in the same day indicate a statistically significant difference (Tukey test, $p<0.05$ ).

a constant level of TMA during the storage of fish is consistent with the fact that TMA accumulation is due to bacterial activity (36), which was virtually absent from the chitosancoated samples. It may therefore be concluded that chitosan coatings inhibit bacterial growth and reduce the accumulation of TMA, resulting in an extension of the shelf life of sliced salmon.

2-Thiobarbituric Acid Value (TBA). TBA measures the level of compounds that are responsible for off-flavors/odors and is particularly important during the later stages of lipid oxidation. Lipid oxidation is a second important factor in food deterioration. The TBA value is a widely used index of lipid oxidation, measuring the malonaldehyde (MDA) content (56). MDA forms from hydroperoxides, which are the initial reaction products of polyunsaturated fatty acids with oxygen (57).

Changes in TBA value are shown in Figure 4. The TBA value of the control fish samples was significantly $(p<0.05)$ higher than the corresponding value of the coated samples during storage at $0{ }^{\circ} \mathrm{C}$. Fan et al. (35) showed that $2 \%$ of chitosan coating clearly inhibited lipid oxidation in fish flesh during frozen storage showed $0.83 \mathrm{mg}$ of $\mathrm{MDA} / \mathrm{kg}$ after 30 days of frozen storage. The initial TBA value of the control samples was $0.29 \pm 0.02 \mathrm{mg}$ of MDA $/ \mathrm{kg}$ of fish, increasing to $1.76 \pm 0.04$ $\mathrm{mg}$ of MDA $/ \mathrm{kg}$ of fish after 18 days of storage (Figure 4). The final TBA value of coated samples was $1.08 \pm 0.04 \mathrm{mg}$ of MDA/ $\mathrm{kg}$ of fish after 18 days of storage. Connel (36) reported that TBA values of 1-2 $\mathrm{mg}$ of MDA/ $\mathrm{kg}$ of fish flesh are usually regarded as the limit beyond which fish will normally develop an undesirable odor.

The coating process involves wetting of the product to be coated by the coating solution and possible penetration of the solution into the skin (40), this process being an important factor for the development of an excellent gas barrier. Fan et al. (35) reported that chitosan coatings reduce lipid oxidation in fish fillets. Both antioxidant and oxygen barrier properties of chitosan may have contributed to the control of lipid oxidation in salmon fillets. The antioxidation mechanism of chitosan can be explained by the formation of a stable fluorophore resulting from the reaction of primary amino groups of chitosan with volatile aldehydes such as malondialdehyde, which is derived from fats breakdown during oxidation (41). In addition, chitosan coating and film have been reported to be good barriers to oxygen permeation $(14,15)$. Sathivel et al. (42) showed that chitosan coating applied on the surface of pink salmon fillets may act as a barrier between the fillet and the air surrounding it, thus slowing the diffusion of oxygen into the fillet.

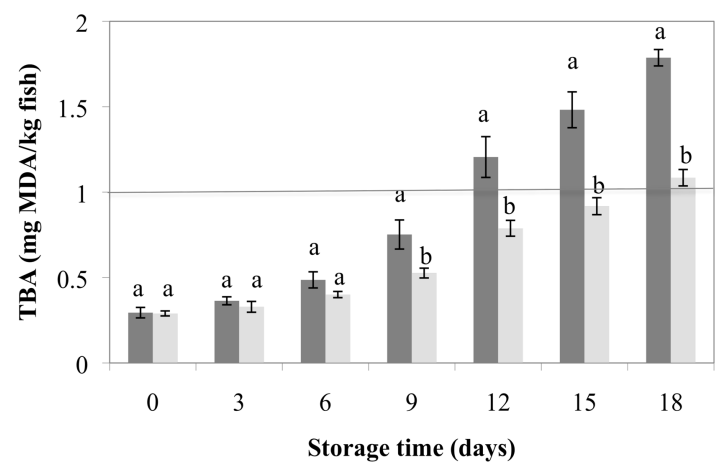

Figure 4. TBA values for control (dark gray bars) and coated (light gray bars) samples of salmon fillet during storage at $0^{\circ} \mathrm{C}$. The horizontal line represents the lower rejection limit in fish flesh, which is between 1 and $2 \mathrm{mg}$ of MDA $/ \mathrm{kg}$. Different letters in the same day indicate a statistically significant difference (Tukey test, $p<0.05$ ).

$K$ Value. Post-mortem degradation of ATP in fish muscle occurs due to endogenous enzymatic activity. This degradation goes through the intermediate products ADP, AMP, IMP, INO, and $\mathrm{Hx}(43-45)$. Most of the adenosine nucleotides disappear quickly because they are degraded to IMP within 1-3 days after fish capture, and as the degradation continues, INO and then $\mathrm{Hx}$ will be produced (45).

The $K$ value, defined as the ratio $(\times 100)$ of nonphosphorylated ATP-breakdown products by the total ATP-breakdown products, has been used as a freshness measure in fish species $(46,47)$. Many factors affect the $K$ value of fish, including fish species, type of muscle, and stress of fish during capture and storage temperature $(48,49)$.

The $K$ values of salmon were calculated from the concentration of nucleotide over the 18 days of storage (Figure 5). Initial $K$ values were 10.6 and $11.5 \%$ for control and treated samples, respectively. A high $K$ value of $49.7 \%$ at day 18 of storage was obtained for the control sample. The coated samples presented a significantly $(p<0.05)$ lower $K$ value $(46.3 \%)$ when compared with the control at the end of the same period. This observation may be possibly explained by the ability of chitosan to minimize the activity of 5-nucleotidase $(50,51)$. Fan et al. (35) showed that $2 \%$ of chitosan was effective in inhibiting the degradation of ATP and extending the frozen storage life of fish samples, showing a $K$ value of $45 \%$ after 30 days of frozen storage.

Freshness indicators related to the breakdown of nucleotides are based on the autolysis of ATP in the muscle. The rapid rise of the $K$ value is entirely due to the sharp decline of IMP in the fish flesh. The loss of IMP through degradation to $\mathrm{HxR}$ and $\mathrm{Hx}$ would cause loss of fish freshness (52).

Microbial Analyses. The composition of fish flesh makes it favorable for microbial growth; therefore, fish spoiling occurs during storage mainly as a result of microbial activity (53). The changes in the microflora of salmon during storage under $0{ }^{\circ} \mathrm{C}$ with or without the addition of chitosan coating are shown in Figure 6. A low bacterial load, a TPC of $3.02 \log _{10} \mathrm{CFU} / \mathrm{g}$, was obtained at the start of the storage period. Similar low initial TPC values have been reported for fresh fish (35).

TPC of chitosan-coated fish samples was found to be the same as that of the control samples during the first 6 days of storage; however, after day 6, a slower increase in TPC values was observed for coated samples when compared with control, 6.88 $\log _{10} \mathrm{CFU} / \mathrm{g}$ being obtained for the treated samples on the $15 \mathrm{th}$ day. This value did not exceed the maximal permissible limit of $7.0 \log _{10} \mathrm{CFU} / \mathrm{g}$, considered as the upper acceptability limit for marine species (ICMSF, 1986; 45), whereas the TPC of control 


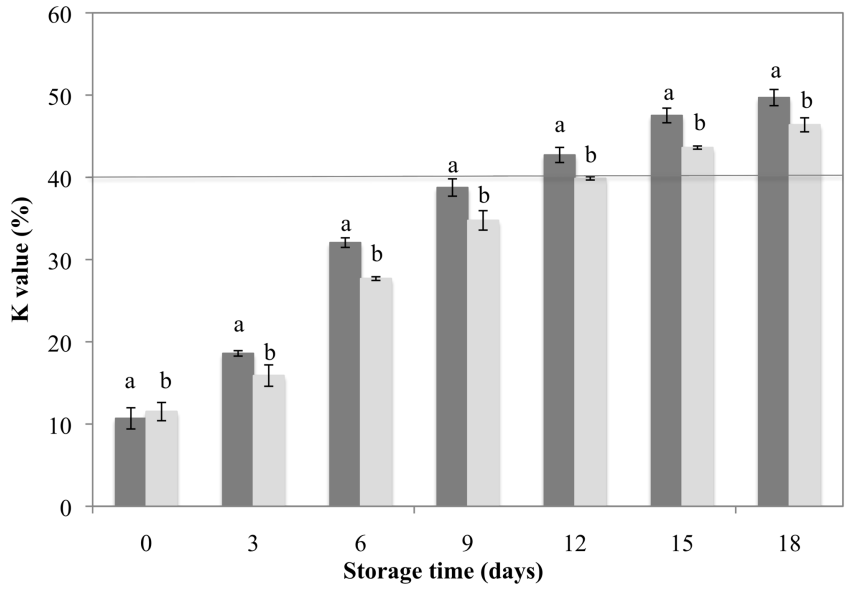

Figure 5. $K$ value for control (dark gray bars) and coated (light gray bars) samples of salmon fillet during storage at $0{ }^{\circ} \mathrm{C}$. The horizontal line represents the rejection limit in fish flesh, which is $40 \%$. Different letters in the same day indicate a statistically significant difference (Tukey test, $p<0.05)$.

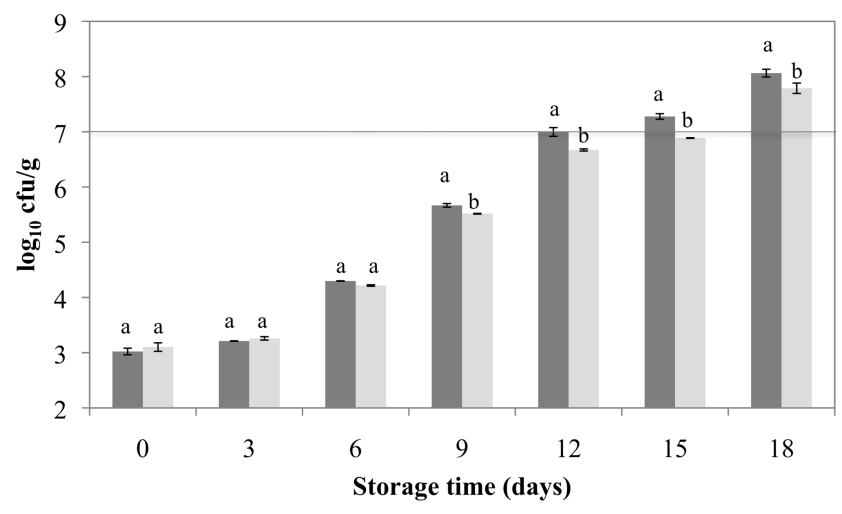

Figure 6. Total aerobic plate count (log CFU/g) for control (dark gray bars) and coated (light gray bars) samples of salmon fillet during storage at $0{ }^{\circ} \mathrm{C}$. The maximum permissible limit for consumption is $7.0 \log _{10} \mathrm{CFU} / \mathrm{g}$, represented by the horizontal line. Different letters in the same day indicate a statistically significant difference (Tukey test, $p<0.05$ ).

samples reached $7.05 \log _{10} \mathrm{CFU} / \mathrm{g}$ on the 12th day of storage. These results show that chitosan coating was effective in extending for 3 days the shelf life of the salmon. These differences may be due to the chitosan antimicrobial activity, which is effectively expressed in aqueous systems $(54,55)$. Fan et al. (35) evaluated the effect of chitosan coating on the quality and shelf life of carp during frozen storage, also demonstrating that chitosan solution coating was effective for extending from 25 to 30 days $\left(6.9 \log _{10}\right.$ $\mathrm{CFU} / \mathrm{g}$ ) the storage life of the fish samples at $-3{ }^{\circ} \mathrm{C}$.

This work shows the usefulness of wettability $\left(W_{\mathrm{s}}\right)$ as a parameter for coating optimization. The fillet surfaces were found to be of low energy, and therefore Zisman's method was used to determine their wettability. Our results showed that the application of chitosan coatings on fillet salmon samples stored at $0{ }^{\circ} \mathrm{C}$ resulted in a reduction of the microbial count at least during 18 days of storage. These coatings may act as an additional hurdle to overcome the contamination of salmon, thus improving the microbiological safety of salmon fillets during storage at $0{ }^{\circ} \mathrm{C}$. Furthermore, edible coatings not only help in retarding the growth of microorganisms but also help in stabilizing chemical constituents, therefore reducing lipid oxidation. This fact suggests an improved efficiency in lipid oxidation control, thus improving fish quality attributes and extending its shelf life.
This work shows that chitosan coatings can be applied to fresh salmon to maintain the chemical quality and extend for 3 days the shelf life of the product during storage at $0{ }^{\circ} \mathrm{C}$. Important data have also been generated on the use of edible coatings on fish and, overall, this is relevant information on the use of such materials for application in this type of food.

\section{LITERATURE CITED}

(1) Duran, A.; Erdemli, U.; Karakaya, M.; Yilmaz, M. T. Effects of slaughter methods on physical, biochemical and microbiological quality of rainbow trout Oncorhynchus mykiss and mirror carp Cyprinus carpio filleted in pre-, in- or post-rigor periods. Fish. Sci. 2008, 74 (5), 1146-1156.

(2) Huang, C. H.; Weng, Y. M. Inhibition of lipid oxidation in fish muscle by antioxidant incorporated polyethylene film. J. Food Process. Preserv. 1998, 22 (3), 199-209.

(3) Kwon, T.; Veen, J. V. Ultraviolet and infrared absorbtion of spectra of malonaldehyde in organic solvents. J. Agric. Food Chem. 1968, 16, 639-642.

(4) Esterbauer, H.; Cheeseman, K. H. Determination of aldehydic lipid peroxidation products: malonaldehyde and 4-hydroxynonenal. Methods Enzymol. 1990, 186, 407-21.

(5) Kilincceker, O.; Dogan, I. S.; Kucukoner, E. Effect of edible coatings on the quality of frozen fish fillets. Lebensm.-Wiss. Technol 2009, 42 (4), 868-873.

(6) Anderson, A. K. Biogenic and volatile amine-related qualities of three popular fish species sold at Kuwait fish markets. Food Chem. 2008, 107 (2), 761-767.

(7) Boyle, J. L.; Lindsay, R. C.; Stuiber, D. A. Adenine-nucleotide degradation in modified atmosphere chill-stored fresh fish. J. Food Sci. 1991, 56 (5), 1267-1270.

(8) Lakshmanam, P. T.; Gopakumar, P. $K$-value, an index for estimating fish freshness and quality. Curr. Sci. 1999, 76 (3), 400-404.

(9) Saito, T.; Arai, K.; Matsuyaoshi, M A new method for estimating the freshness of fish. Bull. Jpn. Soc. Sci. Fish. 1959, 24, 749.

(10) Abbas, K. A.; Mohamed, A.; Jamilah, B.; Ebrahimian, M. A review on correlations between fish freshness and $\mathrm{pH}$ during cold storage. Am. J. Biochem. Biotechnol. 2008, 4, 416-421.

(11) Darmadji, P.; Izumimoto, M. Effect of chitosan in meat preservation. Meat Sci. 1994, 38 (2), 243-254.

(12) Gomez-Estaca, J.; Montero, P.; Gimenez, B.; Gomez-Guillen, M. C. Effect of functional edible films and high pressure processing on microbial and oxidative spoilage in cold-smoked sardine (Sardina pilchardus). Food Chem. 2007, 105 (2), 511-520.

(13) Kim, K. W.; Thomas, R. L. Antioxidative activity of chitosans with varying molecular weights. Food Chem. 2007, 101 (1), 308-313.

(14) Casariego, A.; Souza, B. W. S.; Vicente, A. A.; Teixeira, J. A.; Cruz, L.; Diaz, R. Chitosan coating surface properties as affected by plasticizer, surfactant and polymer concentrations in relation to the surface properties of tomato and carrot. Food Hydrocolloids 2008, 22 (8), 1452-1459.

(15) Souza, B. W. S.; Cerqueira, M. A.; Casariego, A.; Lima, A. M. P.; Teixeira, J. A.; Vicente, A. A. Effect of moderate electric fields in the permeation properties of chitosan coatings. Food Hydrocolloids 2009, 23 (8), 2110-2115.

(16) Cerqueira, M. A.; Lima, A. A.; Souza, B. W. S.; Teixeira, J. A.; Moreira, R. A.; Vicente, A. A. Functional polysaccharides as edible coatings for cheese. J. Agric. Food Chem. 2009, 57 (4), 14561462.

(17) Butler, B. L.; Vergano, P. J.; Testin, R. F.; Bunn, J. M.; Wiles, J. L. Mechanical and barrier properties of edible chitosan films as affected by composition and storage. J. Food Sci. 1996, 61 (5), 953-955.

(18) Caner, C.; Vergano, P. J.; Wiles, J. L. Chitosan film mechanical and permeation properties as affected by acid, plasticizer, and storage. J. Food Sci. 1998, 63 (6), 1049-1053.

(19) Park, S. Y.; Marsh, K. S.; Rhim, J. W. Characteristics of different molecular weight chitosan films affected by the type of organic solvents. J. Food Sci. 2002, 67 (1), 194-197.

(20) Souza, B. W. S.; Cerqueira, M. A.; Martins, J. T.; Casariego, A.; Teixeira, J. A.; Vicente, A. A. Influence of electric fields on the 
structure of chitosan edible coatings. Food Hydrocolloids 2010, 24 (4), 330-335.

(21) Zisman, W. A. Contact angle wettability and adhesion. In Advances in chemistry series, Vol. 43; American Chemical Society: Washington, DC, 1964, pp 1-5.

(22) Busscher, H. J.; Vanpelt, A. W. J.; Deboer, P.; Dejong, H. P.; Arends, J. The effect of surface roughening of polymers on measured contact angles of liquids. Colloids Surf. 1984, 9 (4), 319-331.

(23) Song, B. H.; Springer, J. Determination of interfacial tension from the profile of a pendant drop using computer-aided image processing. 1. Theoretical. J. Colloid Interface Sci. 1996, 184 (1), 64-76.

(24) Rulon, J.; Robert, H. Wetting of low-energy surface. In Wettability; John, B., Ed.; Dekker: New York, 1993; pp 4-77.

(25) Kwok, D. Y.; Neumann, A. W. Contact angle measurement and contact angle interpretation. Adv. Colloid Interface 1999, 81 (3), 167-249.

(26) Malle, P.; Poumeyrol, M. A new chemical criterion for the qualitycontrol of fish - trimethylamine total volatile basic nitrogen (percent). J. Food Prot. 1989, 52 (6), 419-423.

(27) Malle, P.; Tao, S. H. Rapid quantitative-determination of trimethylamine using steam distillation. J. Food Prot. 1987, 50 (9), 756-760.

(28) Kirk, R. S.; Sawyer, R. Pearsons Composition and Analysis of Foods; Longman Scientific and Technica: London, U.K., 1991.

(29) Ryder, J. M. Determination of adenosine triphosphate and its breakdown products in fish muscle by high-performance liquid chromatography. J. Agric. Food Chem. 1985, 33, 678-680.

(30) Michalski, M. C.; Desobry, S.; Hardy, J. Food materials adhesion: a review. Crit. Rev. Food Sci. 1997, 37 (7), 591-619.

(31) Ribeiro, C.; Vicente, A. A.; Teixeira, J. A.; Miranda, C. Optimization of edible coating composition to retard strawberry fruit senescence. Postharvest Biol. Technol. 2007, 44 (1), 63-70.

(32) Carneiro-da-Cunha, M. G.; Cerqueira, M. A.; Souza, B. W. S.; Souza, M. P.; Teixeira, J. A.; Vicente, A. A. Physical properties of edible coatings and films made with a polysaccharide from Anacardium occidentale L. J. Food Eng. 2009, 95 (3), 379-385.

(33) Choi, W. Y.; Park, H. J.; Ahn, D. J.; Lee, J.; Lee, C. Y. Wettability of chitosan coating solution on 'Fuji' apple skin. J. Food Sci. 2002, 67 (7), 2668-2672.

(34) Shenderyuk, V. I.; Bykowski, P. Salting and marinating of fish. In Seafood: Resources, Nutritional Composition and Preservation; Sikorski, Z. E., Ed.; CRC Press: Boca Raton, FL, 1989.

(35) Fan, W. J.; Sun, J. X.; Chen, Y. C.; Qiu, J.; Zhang, Y.; Chi, Y. L. Effects of chitosan coating on quality and shelf life of silver carp during frozen storage. Food Chem. 2009, 115 (1), 66-70.

(36) Connell, J. J. Methods of assessing and selecting for quality. In Control of Fish Quality, 3rd ed.; Fishing News Books: Oxford, U.K., 1990.

(37) Sallam, K. I. Antimicrobial and antioxidant effects of sodium acetate, sodium lactate, and sodium citrate in refrigerated sliced salmon. Food Control 2007, 18 (5), 566-575.

(38) Chung, Y. C.; Su, Y. P.; Chen, C. C.; Jia, G.; Wang, H. I.; Wu, J. C. G.; Lin, J. G. Relationship between antibacterial activity of chitosan and surface characteristics of cell wall. Acta Pharmacol. Sin. 2004, 25 (7), 932-936.

(39) Koutsoumanis, K.; Lampropoulou, K.; Nychas, G.-J. E. Biogenic amine formation and sensory changes associated with the microbial flora of Mediterranean gilt-head sea bream (Sparus aurata) stored aerobically at 0,8 , and $15^{\circ} \mathrm{C}$. J. Food Prot. 1999, 62, 398-402.

(40) Hershko, V.; Klein, E.; Nussinovitch, A. Relationships between edible coatings and garlic skin. J. Food Sci. 1996, 61 (4), 769-777.

(41) Weist, J. L.; Karel, M. Development of a fluorescence sensor to monitor lipid oxidation. 1. Fluorescence-spectra of chitosan powder and polyamide powder after exposure to volatile lipid oxidationproducts. J. Agric. Food Chem. 1992, 40 (7), 1158-1162.
(42) Sathivel, S.; Liu, Q.; Huang, J.; Prinyawiwatkul, W. The influence of chitosan glazing on the quality of skinless pink salmon (Oncorhynchus gorbuscha) fillets during frozen storage. J. Food Eng. 2007, 83 (3), 366-373.

(43) Church, N. MAP fish and crustaceans-sensory enhancement. Food Sci. Technol. Today 1998, 12 (2), 73-83.

(44) Perezvillarreal, B.; Pozo, R. Chemical-composition and ice spoilage of albacore (Thunnus alalunga). J. Food Sci. 1990, 55 (3), 678682.

(45) Ehira, S.; Uchiyama, H. Determination of fish freshness using the K value and comments on some other biochemical changes in relation to freshness. In Seafood Quality Determination; Kramer, D. E., Liston, J., Eds.; Elsevier: Amsterdam, 1987; pp 185-207.

(46) Vázquez-Ortiz, F.; Pacheco-Aguillar, R.; Lugo-Sanchez, M. E.; Villegas Ozuna, R. E. Application of the freshness quality index ( $K$ value) for fresh fish to canned sardines from northwestern Mexico. J. Food Compos. Anal. 1997, 10, 158-165.

(47) Lin, D. M. M. Iced storage characteristics of northern squawfish (Ptychocheilus oregonensis). J. Aquat. Food Prod. Technol. 1994, 3, $25-43$.

(48) Erikson, U.; Beyer, A. R.; Sigholt, T. Muscle high-energy phosphates and stress affect $K$-values during ice storage of Atlantic salmon (Salmo salar). J. Food Sci. 1997, 62 (1), 43-47.

(49) Guizani, N.; Al-Busaidy, M. A.; Al-Belushi, I. M.; Mothershaw, A.; Rahman, M. S. The effect of storage temperature on histamine production and the freshness of yellowfin tuna (Thunnus albacares). Food Res. Int. 2005, 38 (2), 215-222.

(50) Aubourg, S. P.; Pineiro, C.; Gallardo, J. M.; Barros-Velazquez, J. Biochemical changes and quality loss during chilled storage of farmed turbot (Psetta maxima). Food Chem. 2005, 90 (3), $445-452$.

(51) Losada, V.; Pineiro, C.; Barros-Velazquez, J.; Aubourg, S. P. Inhibition of chemical changes related to freshness loss during storage of horse mackerel (Trachurus trachurus) in slurry ice. Food Chem. 2005, 93 (4), 619-625.

(52) Ozogul, F.; Taylor, K. D. A.; Quantick, P. C.; Ozogul, Y. A rapid HPLC-determination of ATP-related compounds and its application to herring stored under modified atmosphere. Int. J. Food Sci. Technol. 2000, 35 (6), 549-554.

(53) Colby, J.-W.; Enriquez-Ibarra, L. G.; Flick, G. J., Jr. Shelf life of fish and shellfish. In Shelf Life Studies of Foods and Beverages; Charalambous, G., Ed.; Elsevier: Amsterdam, The Netherlands, 1993; pp 85-143.

(54) Sudarshan, N. R.; Hoover, D. G.; Knorr, D. Antibacterial action of chitosan. Food Biotechnol. 1992, 6 (3), 257-272.

(55) Wang, G. H. Inhibition and inactivation of 5 species of foodborne pathogens by chitosan. J. Food Prot. 1992, 55 (11), 916-919.

(56) Srikar, L. N.; Hiremath, J. G. Fish preservation I. Studies on changes during frozen storage of oil sardine. J. Food Sci. Technol. 1972, 9, 191-193.

(57) Fernandez, J.; Perez-Alvarez, J. A.; Fernandez-Lopez, J. A. Thiobarbituric acid test for monitoring lipid oxidation in meat. Food Chem. 1997, 59, 345-353.

Received for review June 19, 2010. Revised manuscript received September 13, 2010. Accepted September 20, 2010. B.W.S.S. acknowledges the Coordenação de Aperfeiçoamento de Pessoal de Nível Superior (CAPES, Brazil) for his fellowship, M.A.C. and J.T. M. gratefully acknowledge the Fundação para a Ciência e Tecnologia (FCT, Portugal) for their fellowships (SFRH/BD/23897/2005 and SFRH/BD/32566/2006, respectively), and H.A.R. gratefully acknowledges the ALBAN-European Union Programme of High Level Scholarships for Latin America. 